\title{
What influences diet quality in older people? A qualitative study among community-dwelling older adults from the Hertfordshire Cohort Study, UK
}

\author{
Ilse Bloom ${ }^{1,2, *}$, Wendy Lawrence ${ }^{1,2}$, Mary Barker ${ }^{1,2}$, Janis Baird', Elaine Dennison ${ }^{1}$, \\ Avan Aihie Sayer ${ }^{1,3,4,5}$, Cyrus Cooper ${ }^{1,6}$ and Sian Robinson ${ }^{1}$ \\ ${ }^{1} M R C$ Lifecourse Epidemiology Unit, University of Southampton, Southampton General Hospital, Southampton SO16 \\ 6YD, UK: ${ }^{2}$ NIHR Southampton Biomedical Research Centre in Nutrition, Southampton, UK: ${ }^{3}$ NIHR Newcastle \\ Biomedical Research Centre in Ageing and Chronic Disease, Newcastle University and Newcastle upon Tyne NHS \\ Foundation Trust, Newcastle upon Tyne, UK: ${ }^{4}$ Ageing Geriatrics \& Epidemiology, Institute of Neuroscience and \\ Institute for Ageing, Newcastle University, Newcastle upon Tyne, UK: ${ }^{5}$ NIHR Collaboration for Leadership in Applied \\ Health Research and Care: Wessex, Southampton, UK: ${ }^{6}$ NIHR Musculoskeletal Biomedical Research Unit, University \\ of Oxford, Oxford, UK
}

Submitted 17 February 2017: Final revision received 10 May 2017: Accepted 11 May 2017: First published online 20 July 2017

\begin{abstract}
Objective: To explore influences on diet in a group of community-dwelling older adults in the UK.

Design: Data were collected through focus group discussions with older people; discussions were audio-recorded, transcribed verbatim and transcripts analysed thematically.

Setting: Hertfordshire, UK.

Subjects: Participants were sampled purposively from the Hertfordshire Cohort Study, focusing on those whose diets had been assessed at two time points: 1998-2001 and 2011.

Results: Ninety-two adults participated (47\% women; 74-83 years) and eleven focus groups were held. A number of age-related factors were identified that were linked to food choices, including lifelong food experiences, retirement, bereavement and medical conditions, as well as environmental factors (such as transport). There appeared to be variability in how individuals responded to these influences, indicating that other underlying factors may mediate the effects of age-related factors on diet. Discussions about 'keeping going', being motivated to 'not give up', not wanting to be perceived as 'old', as well as examples of resilience and coping strategies, suggest the importance of mediating psychological factors. In addition, discussion about social activities and isolation, community spirit and loneliness, indicated the importance of social engagement as an influence on diet. Conclusions: Interventions to promote healthier diets in older age should take account of underlying psychological and social factors that influence diet, which may mediate the effects of age-related factors.
\end{abstract}

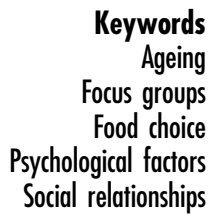

eywords

us groups

Food choice

Social relationships
Although poor diet quality is common in older people ${ }^{(1-4)}$, the determinants of dietary choices and quality in later life are poorly understood. Much of the evidence to date is crosssectional and largely fragmented, particularly regarding how factors interact to impact on diet. The lack of longitudinal evidence is particularly problematic since the ageing process itself is often accompanied by physiological, psychological and social changes that can affect food consumption. Importantly, the variability in diet across the older population suggests that some older adults are able to adapt to these changes and maintain diet quality, while others are not ${ }^{(5)}$.
There is increasing evidence that social factors such as marital status, living arrangements and frequency of social contact are important influences on older people's $\operatorname{diets}^{(6-8)}$. For example, both living alone and having less frequent contact with friends have been found to exacerbate the negative effect of widowhood on $\operatorname{diet}^{(6,9)}$; other studies have highlighted roles of social isolation, lack of social support and lack of participation in leisure $\operatorname{activities}^{(8,10-12)}$.

Less is known about the influence of psychological factors on diet in older age. In younger women, 
a perceived lack of control over life is linked to diets of poorer quality ${ }^{(13)}$ and appears to mediate effects of social disadvantage on diet. In comparison, there is a gap in our understanding of the role of these factors in older age and how they impact on the effects of illness, disability and disadvantage on diet. Findings from Canada ${ }^{(5)}$ have highlighted the roles of resilience (a process comprising positive adaptation despite significant adversity $\left.{ }^{(14)}\right)$ and self-efficacy (an individual's belief in his/her own ability to achieve a desired outcome), which is consistent with a recent study from Japan ${ }^{(15)}$ that found that psychosocial factors, including increased self-efficacy and increased social influence, attenuated the association between lower socio-economic status and poorer diets in older people.

Gaining insight into what supports older adults to eat well will be important in the development of interventions to promote diet quality and enhance healthy ageing. The present study uses qualitative methodology to explore subjective experiences and attitudes, to provide deeper insights. It uses quantitative longitudinal data on diet quality as a starting point to enable comparison of individuals whose diet quality has declined and those whose diets remained stable over time. The primary aim was to explore influences on diet among community-dwelling older people in the UK; the secondary aims were to gain insight into gender differences and factors linked to differences in diet stability in older age.

\section{Methods}

\section{Participants}

Hertfordshire Qualitative Study (HQS) participants were selected from an established cohort, the Hertfordshire Cohort Study $(\mathrm{HCS})^{(16)}$, and included participants whose diets had been assessed at two time points. Between 1998 and 2003 (first time point), the diets of 1677 men and 1540 women, taking part in the HCS, were assessed by an administered $\mathrm{FFQ}^{(17)}$. In 2004-2005, 642 participants, resident in East Hertfordshire, took part in a sub-study that collected musculoskeletal data. In 2011, 592 of these participants were further approached, of whom 443 (75\%) agreed to be followed up ${ }^{(18)}$; at this point (second time point), diet was reassessed. A prudent diet score, derived from a principal component analysis of the dietary data, was calculated for each participant based on his/her consumption of twenty-four indicator foods ${ }^{(19)}$ and was used as an indicator of diet quality. Prudent diet scores calculated using these indicator foods have been shown to be highly correlated with scores calculated from a complete dietary assessment (0.912 in men, 0.904 in women) and they showed comparable associations with blood biomarkers $^{(18)}$. A high score indicated frequent consumption of fruit, vegetables, wholegrain cereals and oily fish. Changes in diet scores over the 10-year period were calculated. While in men average diet quality remained stable with increasing age, in women there was an overall decline: mean change in diet score per year 0.008 (sD 0.099) in men and -0.025 (sD 0.108) in women ${ }^{(12)}$.

Of the 443 HCS participants with follow-up dietary data, 408 (still alive and taking part in the study) were approached and invited to attend a focus group to discuss influences on diet and barriers to eating healthily. These participants were divided into two groups according to change in diet over the past decade, defined using change in prudent diet scores. 'Diet-declined' and 'diet-stable' participants took part in different focus groups. Of the 408 participants approached, ninety-two (23\%) participants (forty-three women and forty-nine men; mean age 78 years) were successfully recruited into the study; the remaining 316 people did not take part for various reasons (unavailability in the study time frame, non-response to invitation letter or unwillingness). In comparison with the 316 HCS participants who did not take part, there were no differences in terms of age, education or social class; however, the ninety-two participants had slightly healthier diets: mean diet score 0.476 (sD 1.429), compared with 0.117 (SD 1.205) in those who did not take part $(P=0 \cdot 017)$.

We selected focus groups as the method for data collection as they draw on the communication and interaction between research participants in order to generate data and are a useful method to investigate complex behaviours, such as dietary behaviours as is the case for the present study. Sufficient focus groups were conducted both to reach the point of saturation, the point at which no new information or themes were observed in the data ${ }^{(20)}$, as well as to ensure approximately similar numbers of participants from the groups that we aimed to compare (men $v$. women; diet-declined $v$. diet-stable).

All participants were provided with an information sheet explaining the study and the nature of the discussion. Written informed consent was obtained from everyone before discussions began.

\section{Procedure}

Participants were contacted by post with an invitation letter, a participant information sheet detailing all important aspects of the study and a reply slip to indicate whether they would be willing to take part. If there was no response from a potential participant after two weeks, a reminder letter was sent. Thereafter, no further contact was made about this study. Willing participants were contacted by I.B. by telephone to arrange a convenient time for them to attend a focus group. Focus groups were held in a centrally located community venue in the town of Hertford, UK in midMarch, end May/beginning June and end September 2014. Upon arrival, W.L. and I.B. introduced themselves to participants, attendees were reimbursed for any travel costs incurred and refreshments were provided. Participants did not receive any further incentives for their participation. W.L. and I.B. worked as a pair, taking turns to moderate and 
observe the discussions. W.L. is an associate professor of health psychology with experience and expertise in qualitative methods, including running focus groups, and I.B. is a research nutritionist with training in qualitative research and some experience conducting focus groups. Both researchers were present at every focus group, except for the last one where only I.B. was present due to practical constraints. Focus group discussions lasted between 75 and 99 min, with an average of approximately $1.5 \mathrm{~h}$. Focus groups were guided by a semi-structured discussion guide developed by the research team, based on a literature review and discussions with nutritionists, epidemiologists and social scientists in the field (see online supplementary material for the full discussion guide). Discussions were audio-recorded and transcribed verbatim.

\section{Data analysis}

Transcripts were analysed thematically ${ }^{(21)}$; the process began with identifying initial codes from transcripts to be refined into themes. A coding framework was developed to represent emergent themes, which were identified using inductive coding, a process of coding the data without trying to fit it into a pre-existing coding frame (i.e. datadriven $)^{(21)}$. All transcripts were double-coded and analysed using a constant comparative approach ${ }^{(22)}$, whereby each theme was compared with the others and assessed for similarities and differences, driven by the study's central purpose (i.e. to explore influences on diet in older age, as well as any gender differences and differences between 'diet-declined' and 'diet-stable' groups). Both moderator and observer were involved in the data analysis to ensure that it was representative of the groups' views and they met regularly to discuss any disagreements, make suggestions for amendments and agree the coding framework. The themes were developed and depicted in a thematic map to illustrate how they link to form the interpretation presented here. Analyses took place at the group level as individuals were not identifiable from the audio-recording.

\section{Results}

\section{Focus group characteristics}

Eleven focus group (FG) discussions were held (see Table 1): six with participants whose diet quality had declined ( $n$ 41), five with participants whose diets had remained stable over time ( $n$ 51). All but one group were held separately for men and women in order to examine differences by gender. Of the ninety-two participants, $47 \%$ were female and their age range was $74-83$ years (mean 78 years). There was a similar spread of manual social class and non-manual social class participants, both within each category of focus group, as well as within each individual group. Numbers of participants in each focus group ranged from five to twelve, and all were white British, born in Hertfordshire in 1931-1939.

\section{Thematic analysis}

Analysis of the data, whereby themes were identified in an inductive (data-driven) process and then thematically coded and analysed using a constant comparative approach, revealed that a number of distinct themes appeared to be important influences on diet. A thematic map was created to depict these themes and this was developed into a hypothetical model to depict the relationships between the themes (Fig. 1). This shows how we propose the themes might interrelate to impact on diet. Four initial themes are proposed as contextual factors:

1. Historical influences on and current beliefs about food.

2. Retirement and bereavement.

3. Age-related conditions/symptoms.

4. Food environment.

Discussions with participants revealed two additional themes that appeared both to have a direct influence on diet and also to mediate the influence of the four contextual factors on diet; these themes are thus hypothesised to be underlying factors in this interpretation of the data:

5. Psychological/personal factors.

6. Social engagement.

The relationship between the contextual factors and the two underlying factors is seen as dynamic and bidirectional. The result of the interaction between the contextual and underlying factors determines how individuals make food choices and construct their diets, captured in the final theme:

7. Food-related habits (e.g. types and quantities of foods eaten, methods used to prepare food/meals).

These themes are set out below and illustrated with example quotes.

In addition to our primary aim, to explore influences on diet among community-dwelling older people, the study was designed to address two secondary aims: to explore differences (i) between 'diet-declined' (DD) and 'diet-stable' (DS) groups, and (ii) between men (M) and women (W). However, our analysis did not reveal any obvious differences between the diet groups and revealed few gender differences. Therefore, the Results section focuses on the themes (listed above) that address the primary aim; where appropriate, comments on gender differences are also given.

\section{Historical influences on and current beliefs about food}

All groups in the present study described the importance of their upbringing and past experiences on the foods they currently eat:

'My mother was a great cook and she taught me how to skin rabbits [laughter] and pluck chickens ... she taught me all sorts of things and I continue that today ... we eat basic and that's what I've been brought up on.' (FG1W DD) 
Table 1 Characteristics of study participants by type of group interviewed; community-dwelling older adults from the Hertfordshire Cohort Study, UK, 2014

\begin{tabular}{|c|c|c|c|c|c|}
\hline & $\begin{array}{c}\text { Women, } \\
\text { diet-declined }\end{array}$ & $\begin{array}{c}\text { Men, } \\
\text { diet-declined }\end{array}$ & $\begin{array}{l}\text { Women, } \\
\text { diet-stable }\end{array}$ & $\begin{array}{c}\text { Men, } \\
\text { diet-stable }\end{array}$ & $\begin{array}{l}\text { Men and women, } \\
\text { diet-stable }\end{array}$ \\
\hline No. of focus groups conducted & 3 & 3 & 2 & 2 & 1 \\
\hline Total no. of participants & 20 & 21 & 21 & 23 & 7 \\
\hline Mean age (years) & 78 & 78 & 78 & 78 & 80 \\
\hline \multicolumn{6}{|l|}{ Age left education, $\leq 14$ years } \\
\hline$n$ & 6 & 3 & 1 & 3 & 1 \\
\hline$\%$ & 30 & 14 & 5 & 13 & 14 \\
\hline \multicolumn{6}{|l|}{ Age left education, $\leq 15$ years } \\
\hline$n$ & 14 & 18 & 20 & 20 & 6 \\
\hline$\%$ & 70 & 86 & 95 & 87 & 86 \\
\hline \multicolumn{6}{|l|}{ Social class, non-manual } \\
\hline$n$ & 10 & $\begin{array}{c}8 \\
\text { (2 missing) }\end{array}$ & 9 & $\begin{array}{c}11 \\
\text { (1 missing) }\end{array}$ & 5 \\
\hline $\begin{array}{l}\text { Social class, manual } \\
n\end{array}$ & 10 & 11 & 12 & 11 & 2 \\
\hline
\end{tabular}

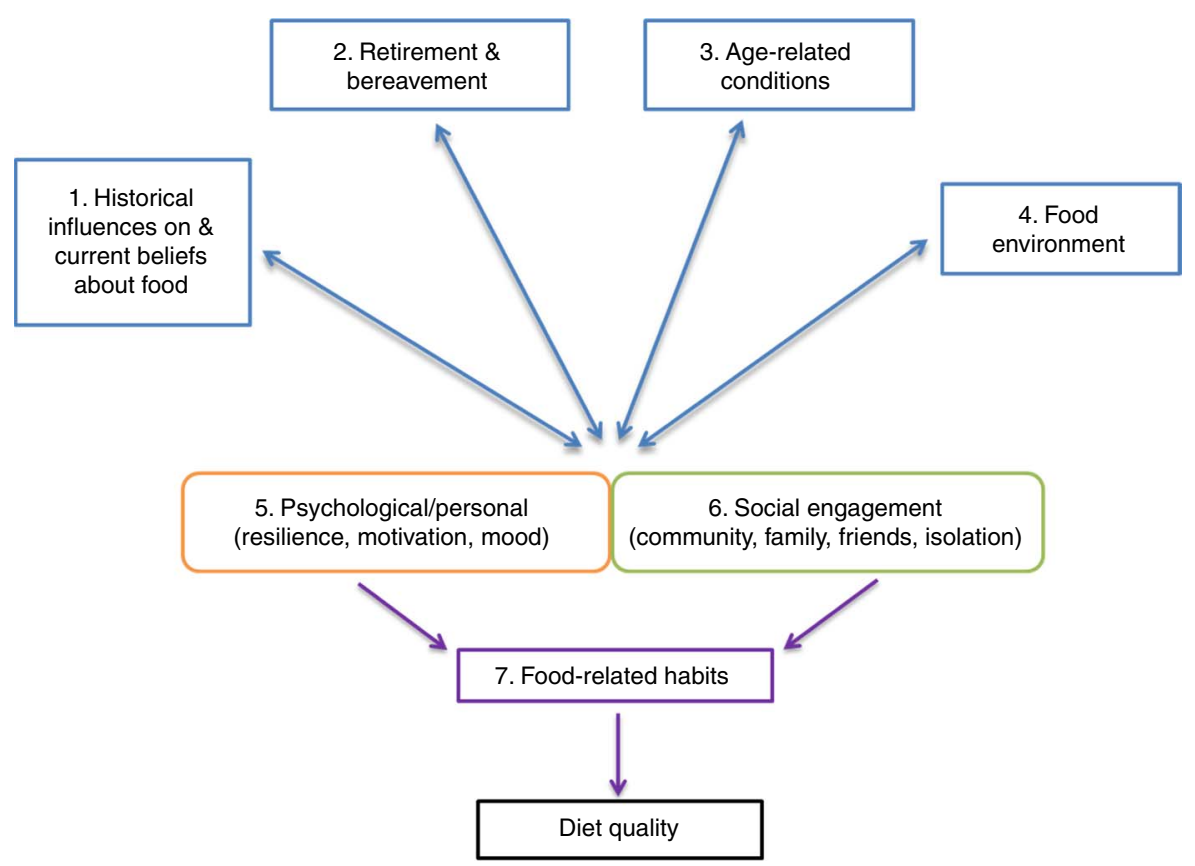

Fig 1 Hypothetical model of the relationships between the themes and potential routes to impact on diet quality in older age

But discussions conveyed that a general shift towards healthier eating habits was guided by current messages and beliefs about what constituted 'healthy', including less fat, sugar, salt:

'I know that we all eat a lot more fish than we used to, and probably more chicken, but a great deal less red meat ... I think because in the media there's been quite a lot about it not being good for you.' (FG9W DS)

\section{Retirement and bereavement}

Most spoke of the impact retirement had had on their lifestyles and particularly on their food habits. One outcome was having more time to prepare food and another was how the new daily structure led to changes in eating patterns:

'I've cut out the two cooked meals a day 'cos when I was in the office I had a restaurant and ... had a proper meal, but when I got home in the evening my wife hadn't had anything so I'd keep her company with a cooked meal. Now ... we just have a cooked lunch and then have a lighter meal.' (FG10M DS)

Following bereavement there were often significant changes to cooking or eating behaviour. The impact on diet following the loss of a partner appeared to affect men 
and women differently. For women, the loss of their partner elicited a range of differing responses in relation to eating, both positive and negative. Women who had lost their partner felt less motivated to cook for themselves, as is described further on. Some tried different foods or went to different places to eat:

'I have a sister-in-law ... and our husbands died within six months of each other and I decided to take her out and we went to [restaurant] and ooh she'd never been anywhere like that, it was wonderful so we've been there several times.' (FG4W DD)

Some had difficulty in accessing the shops, since it was their husband who had done most of the driving:

'My husband died and so I haven't got the car now ... I didn't drive a lot ... I am lucky because if I go shopping, I've got my cousin's husband, always picks me up you know and takes me home.' (FG4W DD)

For men, the primary outcome from the loss or illness of their partner appeared to relate to their ability or motivation to learn or continue to cook. Men largely spoke about having to adapt after losing the person who did most of the cooking. Some learnt to cook and found enjoyment in this; others found alternative solutions such as opting for ready-meal deliveries.

'Well ten years ago I suddenly found myself on my own as my wife suddenly died ... so I suddenly found I had to learn how to cook, and anyway I found that I liked to steam all my vegetables mainly because you could do it all in one pot and you only had one to wash up.' (FG3M DD)

'My main meals are prepared meals you know microwave meals ... I have them delivered from a frozen food company ... I feel rather lazy [laughter] ... I've been doing that for must be three or four years now ... I didn't take much notice of what she was doing unfortunately.' (FG2M DD)

\section{Age-related conditions}

Having a smaller appetite as a result of the natural ageing process was discussed in all groups and many considered portion sizes to be too large when eating out. All groups discussed making changes to their diets, such as choosing or avoiding certain foods, due to medical conditions or medication they were taking. Furthermore, most groups spoke about how physical incapacity or decline had affected food-related activities:

'My knees are so bad now I just don't walk far ... I used to drive but I had to give it up, but I wish I could drive now, it would be easy as I could go down and get my own shopping. I miss doing the shopping.' (FG4W DD)

\section{Food environment}

Price or getting value-for-money was widely discussed, as well as availability and quality of foods. Many spoke about issues with accessing shops or food-related activities:

'We used to walk down for tea to Hertford and catch the bus back 'cos it's uphill, but you can't rely on the buses now so we've stopped doing that.'

(FG7W DS)

Women who lived alone had difficulty finding smaller portions, with supermarkets not catering for the single person and a lack of availability of small shops, such as local butchers:

'If you're on your own, supermarkets don't really cater for single portions.' (FG7W DS)

It is hypothesised that there are two underlying factors (presented below), namely psychological/personal factors and social engagement, that impact on how older people respond to and cope with the influences identified above.

\section{Psychological/personal characteristics}

Our analyses identified a series of contextual and underlying themes that describe influences on diet in older age. One of the underlying themes identified in the present study was the role of psychological and personal factors. A frequently cited driver apparent in these discussions was the need to 'keep going', by being positive and maintaining an interest in life, for fear of being a burden on others or losing their health/independence, like others (peers) have. Participants spoke of wanting to be part of the wider community and to be able to do the things that they had always done, including cooking and eating well. This, along with other explicit references to being motivated to 'not give up' and to not be perceived and treated as 'old', as well as implicit examples of resilience and coping strategies, highlights the importance of resilience and self-efficacy in overcoming dietary setbacks, and suggests an important mediating role of psychological and personal factors on diet. A consistent message from the discussions was the importance of staying positive and being motivated to keep healthy and independent to avoid having to rely on others:

W1: 'You just do it.'

W4: 'You must be positive ...'

W2: 'Motivation ...'

W3: 'I think it's fear of having to rely on other people.'

W4: 'Just like you're going home tonight [you want] a meal, so you're going to cook it, aren't you?' (FG7W DS) 
There was an emphasis on not being regarded as old, or accepting that old age meant behaving in a certain way, and on wanting to remain part of the wider community:

'Making sure you can keep doing all the things you did all your life ... and that's only by keeping on doing exactly what you've always done, not suggesting that you're too old anymore ... that's my policy.' (FG8M DS)

'My daughter always says "Why do you like to go out shopping on a Saturday mum?" It's because I like to be with people of all ages ... you go out in the week ... it's like an old people's club.' (FG9W DS)

For most groups, cooking and food were viewed as a priority:

Moderator: 'And what kind of priority is there for food in everybody's lives?'

M: 'Oh, number one ... I'm still on me own but I'm still ... making meat puds and all that.' (FG2M DD)

For all groups, taste and enjoying food were significant influences on food choices and it was evident that for some this may be more important than potential health benefits:

'I eat what I wanna eat. I know I have a fat belly as you can see. I eat butter, milk, cream, everything, you name it I'll have it. 'Cos you know life's too short, you have what you want.' (FG8M DS)

Both genders spoke of being too lazy, not bothering to cook or not enjoying cooking, but this appeared to be more dominant for women. This seemed to be linked with the issue of eating alone and no longer having the role of providing meals for someone else (described below in the section about social engagement), and was another aspect of the interaction between gender and how bereavement/ loneliness influenced food-related behaviours:

'I admit I'm lazy, I don't bother to cook dinners very often ... I very rarely eat meat and I don't eat chicken so I find it really difficult to eat proper, so possibly I have too much things on toast ... I never used to be like this I used to eat... possibly since I've been on my own I think ... I used to cook dinners every day, we used to be quite big meat eaters but I can't eat much meat now ...'

Moderator: 'Do you enjoy cooking?'

'No, not now.' (FG6W DD)

\section{Social engagement}

In addition, there was much discussion about social activities and isolation; of community spirit and loneliness - indicating the importance of maintaining and developing ways to ensure social engagement, the other underlying theme identified in the present study. For those who have a good level of social engagement, it may be easier to cope with the process of ageing and other contextual influences we identified. There was recurrent discussion about taking part in various social activities and clubs. The motivation to keep going and not be perceived as old led these participants to seek opportunities for social engagement. Eating out or with friends/family was widely spoken of as a key social activity:

'We have a monthly pub lunch ... and you see people there that you probably haven't seen for donkey's years ... the food is dreadful [laughter] - it really is! I said to a bloke the other day "I could never stop coming" because I only see him ... when I go there ... I moan about it something rotten but you go again and that is very good for socialising.' (FG2M DD)

Friends also played an important role in facilitating engagement with a range of social activities, not necessarily food-related.

There was discussion of the influence of family members on eating habits; family members, such as children or grandchildren, had an important influence on participants' eating habits:

'I do me own cooking ... 'cos I'm on me own now but my daughter occasionally brings things in for me to eat.' (FG5M DD)

Women were more likely to speak about the loneliness of eating alone or not having a supportive community around them, particularly following bereavement. They emphasised the importance of family, friends and community in supporting them through difficult times and ensuring they did not become isolated. For women, eating alone was seen as a difficult or lonely activity; they spoke of the importance of having a partner or others to cook for:

'I find um eating on your own, you take ages cooking a meal and you sit at the table ... and within a few minutes you've eaten it and there's no one to talk to.' (FG1W DD)

The role of friends or family in motivating and supporting women to take part in social activities, especially following the loss or illness of a partner, was particularly important:

'Luckily I've got good family and friends, so they would rally around and say "Oh come on go and do this". But it is a completely different life because I find ... friends ... if they're all couples when you're on your own in the group ... you feel more alone, you think "Well I'd rather be at home".' (FG7W DS) 
Discussion about the importance of having supportive neighbours or community environment was also more prominent for women:

'The cul-de-sac I live in, not one person has come up to me and said "I'm ever so sorry your husband died". I could do with somebody caring, not for me but about me, 'cos at the moment it's eleven months today my husband died and I am lonely ... it's horrible, nobody comes up to you and says "Want a cup of tea?" or anything.' (FG1W DD)

The above described analysis suggests that the interaction between contextual and underlying themes impacts differently on people's food-related habits, which could underlie differences in dietary quality observed across the population.

\section{Food-related habits}

All participants had a great deal to say about how they prepared food and what they liked to eat. For instance, preparing one-pot dinners, cooking extra and freezing were strategies to dealing with eating alone. All groups discussed the division of food-related tasks within the household; two main patterns emerged: the wife doing most or all of the shopping or cooking, and the husband and wife sharing the tasks. For women, it was clear that their husbands' likes and dislikes played a major role in influencing the types of foods they cooked and hence the current family food habits. At the same time, many men appeared to prefer home-cooked meals, cooked by their wives, to meals eaten out.

\section{Discussion}

The current study suggests that social and psychological factors may mediate the influence of background characteristics on the diets of older people, which to our knowledge has not been demonstrated before. The study also generated testable hypotheses as to how this complexity of factors might interrelate to impact on diet.

Our primary aim was to explore what influences older people's diets. Perhaps as expected, various contextual factors relating to the process of ageing had a significant impact on diet. This encompassed experiences over a long lifetime, represented as past and present food influences and beliefs; the impact of retirement, bereavement, medical conditions and symptoms; and the interaction of environmental and ageing factors (such as cost or access to shops, including having a means of transport to get around). All of these potentially constrain food choices, but there appeared to be variability in how individuals responded to these influences, indicating that other underlying factors may condition their effects on diet. We conducted separate focus group discussions with men and women whose diets had declined in recent years and those whose diets had remained relatively stable, making it possible to explore differences between them. All but one group was single-sex, allowing an exploration of gender effects. However, surprisingly, our analysis revealed no obvious differences in influences on diet between diet-stable and -unstable groups. Furthermore, despite evidence of poorer diet quality among older men compared with women ${ }^{(12)}$, we found few differences by gender.

We developed a hypothetical model to illustrate the relationships between the themes identified through analysis of the data, where we suggest how these factors might interact to influence diet. To our knowledge only one other model ${ }^{(23)}$ has sought to comprehensively synthesise the complex interaction between the broad range of influences on dietary choices in later life. Although the models differ in various ways, the influences on dietary choices identified in the present study are essentially similar to those observed by Winter Falk et al. in a US context. The present model explicitly depicts contextual factors related to ageing, such as retirement, bereavement and medical conditions. Our model also highlights the importance of resilience as a psychological/personal factor and suggests an important role of social engagement in mediating the effects of other influences on diet.

Participants talked about eating foods for enjoyment, as opposed to eating to maintain health. It appeared that some believed that changing unhealthy eating habits would not necessarily improve their health, whereas others were convinced that a healthy diet would keep them healthy and independent. These differing outcome expectancies - believing that one's behaviour will lead to a desired outcome - are likely to influence food behaviour in older age ${ }^{(24)}$.

According to social cognitive theory ${ }^{(25)}$, psychological factors such as self-efficacy and outcome expectancies can mediate the influence of environmental or situational factors on an individual's behaviour; if an individual believes he/she can undertake an action and that this will lead to a positive outcome, he/she is more likely to overcome barriers to healthy behaviours and to make changes to these ${ }^{(26)}$.

In line with previous research ${ }^{(27,28)}$ the current study highlighted the importance of life transition points, such as retirement, loss of a partner and onset of illness, in leading to changes in dietary habits. Previous research ${ }^{(29)}$ suggests that older men may be ill-prepared to undertake foodrelated activities when losing their spouse, as women traditionally carried out food-provisioning tasks; while others suggest ${ }^{(30)}$ that particularly for men, poor cooking skills may have a negative influence on diet. Women who had lost their partner felt less motivated to cook for themselves, which is consistent with previous qualitative research in older community-dwelling adults (mostly female) that found that food apathy (lack of interest or enthusiasm regarding eating) influenced $\operatorname{diet}^{(5)}$. A recent 
qualitative study of widowed older women living alone ${ }^{(28)}$ suggests that women adopt new eating patterns in widowhood in a process that is influenced by various factors including their social network.

Previous research has found that older men and women who live alone have worse diet quality than those living with a partner ${ }^{(11,31)}$. A study of adults aged over 50 years in the EPIC (European Prospective Investigation into Cancer and Nutrition) cohort (UK) ${ }^{(6)}$ found that people who were single or widowed had decreased variety of fruit and vegetable intake in comparison to those who were married, in men more than in women. The study found that both living alone and having less frequent contact with friends exacerbated the effect of widowhood on decreasing vegetable variety, suggesting that friends may compensate for the lack of social ties to a partner ${ }^{(6,9)}$.

Research has shown that increased frequency of social contact is associated with healthier dietary habits in older people ${ }^{(6)}$. We have recently shown in the Hertfordshire cohort $^{(12)}$ that greater participation in leisure activities, especially cognitive activities, was associated with smaller declines in diet quality over a 10-year follow-up period. Others $^{(32)}$ found that social relationships, rather than socio-economic status, enhance resilience in older people, when these precede, and continue throughout, the period of adversity. Involvement in leisure activities has been found to become increasingly important with age and could contribute to resilience in older people ${ }^{(33)}$.

Increased social contact might influence diet through various mechanisms, such as increased social support, which can provide encouragement and companionship; social control; increased social influence/social comparison; an increased sense of purpose; meaning in life; and sense of belonging ${ }^{(34)}$. It has been suggested that these pathways could promote positive psychological states that could motivate healthy behaviours, including diet ${ }^{(34)}$.

\section{Strengths and limitations}

Analysis of focus group data is generally conducted at the group level, increasing the likelihood of some views being weighted inaccurately. Although two researchers were present at most focus groups, one of the groups was only attended by one of them. We acknowledge that the current study presents only one possible interpretation of the data and that other interpretations could be possible. However, the study benefits from having input from an experienced multidisciplinary research team. Through a rigorous approach to the analyses, including doublecoding, a high level of quality control was achieved, in order to minimise misinterpretation. A limitation of the study is that the age range of the study population (74-83 years) was determined by the prior quantitative study and does not represent the full age range of older adults (i.e. $\geq 65$ years). Only white, British older adults took part, and participants had slightly healthier diets than members of the cohort who did not take part, such that the findings may not be generalisable to all senior populations. However, as the HCS has been shown to be broadly representative of the wider population of older adults in England ${ }^{(16)}$, there is no reason to believe a vastly different interpretation would be presented if others from this population were sampled. It is a strength of the study that a good sample size was achieved, that included older adults from a range of different social backgrounds, which suggests that the findings could be of relevance to the wider population of older adults in the UK.

\section{Conclusion}

The present study has highlighted the potential importance of underlying social and psychological factors in understanding why, in the face of dietary challenges that commonly accompany ageing, some older people are able to adapt and maintain a healthy diet, while others are not. Hence, future interventions to promote quality of diet and better health in older age may need to consider social engagement and psychological factors (resilience, selfefficacy, outcome expectancies) in their design, as levers for change. The development of a hypothetical model of influences on diet in older age presents the opportunity to test quantitatively the hypothetical relationships between these factors and how they could interrelate to impact on diet in later life.

\section{Acknowledgements}

Acknowledgements: The authors are very grateful to the HCS participants who took part in the study; and thank Dr Tannaze Tinati and Rufia Begum for help and advice with the data analysis. Financial support: This work was supported by the Medical Research Council (MRC) and the National Institute for Health Research (NIHR) Southampton Biomedical Research Centre in Nutrition, a partnership between University Hospital Southampton NHS Foundation Trust and the University of Southampton that is funded by the NIHR. The funders had no role in the design, analysis or writing of this article. Conflict of interest: None. Authorship: I.B. planned and executed data collection, contributed to the data analysis/interpretation and wrote the first draft of the paper. W.L. helped to conceptualise the work, to supervise its execution and contributed to data collection and analysis/interpretation. M.B. contributed to later-stage supervision and data analysis/interpretation. J.B. contributed to oversight of the project and interpretation of the data. C.C., E.D. and A.A.S. were responsible for the design and supervision of the Hertfordshire Cohort Study and provided contributions to oversight of the project. S.R. conceived the study, supervised its execution and contributed to the interpretation of the data. All authors helped to revise and draft 
the manuscript and approved the final version. Ethics of buman subject participation: This study was conducted according to the guidelines laid down in the Declaration of Helsinki and all procedures involving human subjects were approved by the NRES Committee East of England, Hatfield (REC reference: 10/H0311/59). The HCS had ethical approval from the Bedfordshire \& Hertfordshire Local Research Ethics Committee and the West Hertfordshire Local Research Ethics Committee. Written informed consent was obtained from all participants.

\section{Supplementary material}

To view supplementary material for this article, please visit https://doi.org/10.1017/S1368980017001203

\section{References}

1. Elia M, Russell CA \& Stratton RJ (2010) Malnutrition in the UK: policies to address the problem. Proc Nutr Soc 69, 470-476.

2. Maynard M, Gunnell D, Ness AR et al. (2006) What influences diet in early old age? Prospective and cross-sectional analyses of the Boyd Orr cohort. Eur J Public Health 16, 316-324.

3. Elsner RJF (2002) Changes in eating behavior during the aging process. Eat Behav 3, 15-43.

4. Johnson AE, Donkin AJM, Morgan K et al. (1998) Fruit and vegetable consumption in later life. Age Ageing 27, 723-728.

5. Vesnaver E, Keller HH, Payette $\mathrm{H}$ et al. (2012) Dietary resilience as described by older community-dwelling adults from the NuAge study 'if there is a will - there is a way!'. Appetite 58, 730-738.

6. Conklin AI, Forouhi NG, Surtees P et al. (2014) Social relationships and healthful dietary behaviour: evidence from over-50s in the EPIC cohort, UK. Soc Sci Med $\mathbf{1 0 0}$, $167-175$.

7. Sahyoun NR \& Zhang XL (2005) Dietary quality and social contact among a nationally representative sample of the older adult population in the United States. $J$ Nutr Health Aging 9, 177-183.

8. Vesnaver E \& Keller HH (2011) Social influences and eating behavior in later life: a review. J Nutr Gerontol Geriatr 30 , $2-23$.

9. Friedman EM (2014) Good friends, good food ... what more could we want? Assessing the links between social relationships and dietary behaviors. A commentary on Conklin et al. Soc Sci Med 100, 176-177.

10. Romero-Ortuno R, Casey AM, Cunningham CU et al. (2011) Psychosocial and functional correlates of nutrition among community-dwelling older adults in Ireland. $J$ Nutr Health Aging 15, 527-531.

11. Dean M, Raats MM, Grunert KG et al. (2009) Factors influencing eating a varied diet in old age. Public Health Nutr 12, 2421-2427.

12. Bloom I, Edwards M, Jameson KA et al. (2017) Influences on diet quality in older age: the importance of social factors. Age Ageing 46, 277-283.

13. Lawrence W, Skinner C, Haslam C et al. (2009) Why women of lower educational attainment struggle to make healthier food choices: the importance of psychological and social factors. Psychol Health 24, 1003-1020.

14. Luthar SS, Cicchetti D \& Becker B (2000) The construct of resilience: a critical evaluation and guidelines for future work. Child Dev 71, 543-562.

15. Sugisawa H, Nomura T \& Tomonaga M (2015) Psychosocial mediators between socioeconomic status and dietary habits among Japanese older adults. J Nutr Health Aging 19, 130-136.

16. Syddall HE, Aihie Sayer A, Dennison EM et al. (2005) Cohort profile: the Hertfordshire cohort study. Int J Epidemiol 34, 1234-1242.

17. Robinson S, Syddall H, Jameson K et al. (2009) Current patterns of diet in community-dwelling older men and women: results from the Hertfordshire Cohort Study. Age Ageing 38, 594-599.

18. van der Pas S, Castell MV, Cooper C et al. (2013) European project on osteoarthritis: design of a six-cohort study on the personal and societal burden of osteoarthritis in an older European population. BMC Musculoskelet Disord 14, 138.

19. Robinson SM, Jameson KA, Bloom I et al. (2016) Development of a short questionnaire to assess diet quality among older community-dwelling adults. J Nutr Health Aging 21, 247-253.

20. Krueger R \& Casey M (2000) Focus Groups: A Practical Guide for Applied Research, 3rd ed. Thousand Oaks, CA: SAGE Publications, Inc.

21. Braun V \& Clarke V (2006) Using thematic analysis in psychology. Qual Res Psychol 3, 77-101.

22. Boyatzis R (1998) Transforming Qualitative Information: Thematic Analysis and Code Development. London: SAGE Publications Ltd.

23. Winter Falk L, Bisogni CA \& Sobal J (1996) Food choice processes of older adults: a qualitative investigation. $J$ Nutr Educ 28, 257-265.

24. Grembowski D, Patrick D, Diehr P et al. (1993) Self-efficacy and health behavior among older adults.J Health Soc Behav 34, 89-104.

25. Bandura A (1986) Social Foundations of Thought and Action: A Social Cognitive Theory. Englewood Cliffs, NJ: Prentice-Hall.

26. Purdie N \& McCrindle A (2002) Self-regulation, self-efficacy and health behavior change in older adults. Educ Gerontol 28, 379-400.

27. Blane D, Abraham L, Gunnell D et al. (2003) Background influences on dietary choice in early old age. J R Soc Promot Health 123, 204-209.

28. Vesnaver E, Keller HH, Sutherland O et al. (2015) Food behavior change in late-life widowhood: a two-stage process. Appetite 95, 399-407.

29. McDonald J, Quandt SA, Arcury TA et al. (2000) On their own: nutritional self-management strategies of rural widowers. The Gerontologist 40, 480-491.

30. Hughes G, Bennett KM \& Hetherington MM (2004) Old and alone: barriers to healthy eating in older men living on their own. Appetite 43, 269-276.

31. Irz X, Fratiglioni L, Kuosmanen $\mathrm{N}$ et al. (2014) Sociodemographic determinants of diet quality of the EU elderly: a comparative analysis in four countries. Public Health Nutr 17, 1177-1189.

32. Blane D, Wiggins RD, Montgomery SM et al. (2011) Resilience at Older Ages: The Importance of Social Relations and Implications for Policy. ICLS Occasional Paper Series no. 3. London: International Centre for Lifecourse Studies, University College London.

33. Nimrod G \& Shrira A (2014) The paradox of leisure in later life. J Gerontol B Psychol Sci Soc Sci 71, 106-111.

34. Thoits PA (2011) Mechanisms linking social ties and support to physical and mental health. J Health Soc Behav 52, 145-161. 